\title{
Antimicrobial silver-hydroxyapatite composite coatings through two-stage electrochemical synthesis
}

\author{
Cong $\mathrm{Fu}^{\mathrm{a}}$, Xuefei Zhang ${ }^{\mathrm{a}}$, Keith Savino ${ }^{\mathrm{a}}$, Paul Gabrys ${ }^{\mathrm{a}}$, Yun Gao ${ }^{\mathrm{a}}$, Wanaruk \\ Chaimayo $^{\mathrm{b}}$, Banjamin L. Miller ${ }^{\mathrm{b}}$, Matthew Z. Yates ${ }^{\mathrm{a}, *}$ \\ ${ }^{a}$ Department of Chemical Engineering and Laboratory for Laser Energetics, University of \\ Rochester, Rochester, NY, 14627, United States. \\ ${ }^{b}$ Department of Dermatology, University of Rochester, Rochester, NY 14642, United States.
}

\begin{abstract}
A two-stage electrochemical synthesis method was developed to prepare antimicrobial silver-hydroxyapatite (Ag-HA) composite coatings. In the first stage, a titanium substrate was coated with hydroxyapatite (HA) through electrochemical crystallization from aqueous solution. In the second stage, silver nanoparticles were deposited onto the HA layer through electrochemical reduction of aqueous $\mathrm{Ag}^{+}$to $\mathrm{Ag}^{0}$. Silver nanoparticles having a narrow size distribution were found to deposit uniformly on the HA layer. The quantity and size of silver nanoparticles were shown to be controlled by the electrochemical deposition time under constant applied electrical current density. Ag-HA composite coatings were found to be bioactive based upon the promotion of the deposition of additional calcium phosphate onto the Ag-HA coating surface from simulated body fluid. Staphylococcus aureus bacteria growth was inhibited by coatings of Ag-HA, while HA coatings without silver had little effect on growth of the bacteria. The novel composite Ag-HA coatings can potentially be used in orthopedic and dental implants to simultaneously improve osseointegration and prevent post-surgical infection.

Keywords:

Hydroxyapatite, Electrochemical, Composite, Silver
\end{abstract}

${ }^{*}$ Corresponding author

Email address: myates@che.rochester. edu (Matthew Z. Yates) 


\section{Introduction}

Hydroxyapatite (HA) is a calcium phosphate compound that is found naturally as the mineral component of teeth and bone tissue. Orthopedic and dental implants are often coated with HA or related calcium phosphate compounds in order to speed osseintegration following surgery [1]. A number of in vivo and clinical studies have shown that HA promotes the osseointegration of load bearing implants [2-4]. As a result of its bioactivity, HA coatings have been used commercially for decades in dental and orthopedic applications. Commercial HA coatings are most commonly applied to implants using plasma spray [5], but a variety of other low temperature techniques can be used, including sol-gel synthesis [6], electrophoretic deposition [7], and electrochemical crystallization [8]. The electrochemical method allows crystalline HA to be deposited rapidly from aqueous solution under mild operating conditions. In addition, curved surfaces such as dental implant screws and orthopedic fixation pins may be evenly coated electrochemically in a single step. It was recently discovered that sub-micron thick HA coatings deposited electrochemically retain strong electrical polarization that is known to promote osseointegration [9]. The electrochemical technique therefore offers a low cost route for surface modification of implants with HA that has chemical and electrical properties that promote osseointegration. Strongly adherent, sub-micron thick HA layers can be electrochemically synthesized on the surface within a few minutes.

One of the most serious complications following implant surgery is bone infection. To reduce the incidence of bacterial film formation on implant surfaces, local delivery of antibiotics is desirable [10]. In some procedures, surgeons use polymeric bone cement as a carrier for antibiotic release. Bone cements are typically based on non-biodegradable poly(methyl methacrylate), making the cement a non-ideal material for extended drug delivery. Moreover, there is evidence that local delivery of antibiotics significantly increases the likelihood of infection with antibiotic resistant bacteria following implant revision surgery [11]. One of the major concerns with the use of antibiotics is the relatively rapid rate that bacteria can become resistant to treatment $[12,13]$. Rapid clearance of antibiotic molecules from the body requires repeated doses for systemic delivery, and makes extended release through local delivery challenging.

Silver is well known for its broad spectrum antimicrobial activity, and has been gaining increasing attention as an alternative to traditional antibiotic molecules. It has high efficiency and low toxicity for long-term use [14-16]. Silver ions, silver compounds and silver particles have been used in pharmaceuticals and in medical 
devices to replace antibiotics or other antibacterial agents [17-21]. Bacteria may be killed upon surface contact with metallic silver nanoparticles, and through the extended release of low concentrations of silver ions through oxidative dissolution of the nanoparticles [22]. Silver nanoparticles have the advantages of long term antimicrobial activity from a single application, and a low probability of a microorganism developing resistance. A variety of chemical and physical methods have been developed to synthesize silver nanoparticles [23-26]. Among these approaches, the reduction of $\mathrm{Ag}^{+}$to $\mathrm{Ag}^{0}$ is attractive for the potential to rapidly produce large quantities of product at low cost [27-30]. Silver ions can be reduced either chemically or electrochemically, with various synthesis methods allowing key nanoparticle properties such as particle size, size distribution, purity, crystallinity and shape to be controlled. Silver nanoparticles have been formed within thin ceramic coatings made through sol-gel synthesis by chemically reducing $\mathrm{Ag}^{+}$ to $\mathrm{Ag}^{0}$ [31-33].

Silver nanoparticles or silver atoms incorporated into HA coatings provide antimicrobial properties while maintaining the bioactivity of HA. Several methods have been used to create silver-containing HA coatings, including plasma spray [34], sputter coating [35], sol-gel synthesis [36], electrolytic synthesis followed by ion exchange [37], and electrophoretic deposition [38]. In the present study, a novel two-stage coating process is reported in which two electrochemical reactions are carried out in sequence to form a silver-hydroxyapatite (Ag-HA) composite thin film on a titanium substrate. The present study is motivated by the recent discovery that electrochemically synthesized sub-micron thick HA coatings retain strong quasi-permanent electrical polarization [9]. Electrical polarization is known to enhance biomineralization, cell adhesion, cell proliferation, and osseointegration [39-41]. The first stage of the synthesis is the electrochemical crystallization of HA from an aqueous solution onto a titanium substrate acting as a cathode. In the second stage, silver is electrochemically reduced from silver ions in aqueous solution onto the HA-coated titanium. The two stages are carried out under similar operating conditions, offering a rapid low cost implant coating method. The end result is a sub-micron thick HA coating decorated with silver nanoparticles. Separating the process into two stages allows the HA coating properties to be controlled independently of the silver loading. The silver loading can then be controlled in the second without altering the synthesis conditions known to produce polarized HA in the first stage. The resulting Ag-HA coating has the potential to act as an antimicrobial implant surface that inhibits bacterial growth while simultaneously enhancing osseointegration. Previous studies have shown that the loading of silver into HA must be optimized in order to provide an an- 
tibacterial effect without inducing cytotoxicity, as reviewed recently [42]. Future work will examine the cytotoxicity of the Ag-HA coatings made by two-stage electrochemical deposition in order to optimize the silver loading for potential in vivo applications.

\section{Experimental procedure}

\subsection{Materials}

Tris(hydroxymethyl)aminomethane (>99.8\%), $\mathrm{CaCl}_{2} \cdot 2 \mathrm{H}_{2} \mathrm{O}(>99 \%), \mathrm{NaCl}$ (>99.0\%), and $\mathrm{K}_{2} \mathrm{HPO}_{4}(99.99 \%)$ were purchased from Sigma-Aldrich. Aqueous $\mathrm{HCl}$ solution $(37 \%)$ was purchased from Mallinckrodt Chemicals. Titanium (Ti, $0.89 \mathrm{~mm}$ thick) and platinum (Pt, $0.127 \mathrm{~mm}$ thick) foils were obtained from Alfa Aesar. $\mathrm{AgNO}_{3}$ (ACS grade) was obtained from Amresco.

\subsection{Electrochemical crystallization of $H A$}

A pre-cleaned Ti plate $(12.5 \times 12.5 \times 0.89 \mathrm{~mm})$ was used as the cathode while a Pt foil $(25 \times 25 \times 0.127 \mathrm{~mm})$ was used as the anode in the electrochemical crystallization. An electrolyte solution was prepared by dissolving $138 \mathrm{mM} \mathrm{NaCl}$, $50 \mathrm{mM}$ tris(hydroxymethyl)aminomethane, $1.3 \mathrm{mM} \mathrm{CaCl}_{2}, 0.84 \mathrm{mM} \mathrm{K}_{2} \mathrm{HPO}_{4}$ in deionized water. The solution was buffered to $\mathrm{pH}=7.2$ with $37 \% \mathrm{HCl}$. The anode and cathode were immersed into the electrolyte solution. The electrolyte solution was heated in an oil bath to maintain constant temperature. When the temperature of the electrolyte solution arrived at $\sim 95^{\circ} \mathrm{C}$, a constant current density of 12.5 $\mathrm{mA} / \mathrm{cm}^{2}$ (relative to $\mathrm{Pt}$ electrode area) was applied for 2 minutes. The reaction results in selective crystallization of HA onto the titanium cathode.

\subsection{Electrochemical reduction of silver}

After the electrochemical deposition of HA, the electrodes were transferred to a $125 \mathrm{ml}$ aqueous solution of $\mathrm{NaCl}$. The solution was heated to $95^{\circ} \mathrm{C}$ under vigorous stirring. Then $\mathrm{AgNO}_{3}$ having same concentration as the $\mathrm{NaCl}$ was added to the solution immediately before applying a DC electric field. Deposition time, was varied to investigate its effects on $\mathrm{Ag}-\mathrm{HA}$ formation. The electrochemical reaction resulted in selective deposition of $\mathrm{Ag}$ nanoparticles onto the HA coated titanium cathode. 


\subsection{Characterization of the coatings}

Morphology and composition of the samples were examined using a ZeissLeo DSM982 field emission scanning electron microscope (SEM) equipped with a Phoenix EDAX energy dispersive X-ray spectrometer (EDX). Surface composition was obtained with a Kratos AXIS Ultra DLD X-ray photoelectron spectrometer (XPS), equipped with a monochromatic $\mathrm{Al}$ anode $\mathrm{X}$-ray gun $(\mathrm{K} \alpha=1486.6 \mathrm{eV})$. For crystal structure determination, four identically synthesized samples were scraped off the titanium substrate and combined to obtain enough material in the form of powder to analyze with X-ray diffraction (XRD). The powder was then analyzed with a Philips PW3020 XRD spectrometer using $\mathrm{Cu} \mathrm{K} \alpha$ radiation $(\lambda=$ $1.5418 \AA$ ).

\subsection{Mineralization from simulated body fluid}

Solutions of $1.5 \times$ simulated body fluid (SBF) were prepared following the literature [43]. Ag-HA composite coatings were placed into vials containing $5 \mathrm{ml}$ of $1.5 \times \mathrm{SBF}$ at $37^{\circ} \mathrm{C}$ with $\mathrm{pH}$ of 7.25 . After 24 hours, the samples were taken out of the solution, rinsed with deionized water, and placed in a desiccator to dry. The mineralization was examined using SEM of the dried samples. Electrochemically synthesized HA coating without silver deposition was used as a control sample for comparison.

\subsection{Antibacterial activity}

A solution of E. coli (BL21(DE3)) bacteria in tryptic soy broth was grown overnight with shaking at $37^{\circ} \mathrm{C}$. The bacteria concentration was then diluted with tryptic soy broth until the solution's absorbance value at $490 \mathrm{~nm}$ was 0.01 . Bacteria growth curves were produced by placing $3 \mathrm{HA}$ and $3 \mathrm{Ag}-\mathrm{HA}$ samples into wells of a 24 well plate. Each well was then filled with $2 \mathrm{ml}$ of bacteria suspension, as well as three control wells with just bacteria suspension. The samples were then incubated at $37^{\circ} \mathrm{C}$. Bacteria growth was measured at various times $(0$ hr, $2 \mathrm{hr}, 4 \mathrm{hr}$, and $8 \mathrm{hr}$ ) using light scattering at $490 \mathrm{~nm}$ (PerkinElmer EnSpire Multimode Plate Reader) by placing $1200 \mu \mathrm{L}$ of bacteria solution into 6 wells ( $200 \mu \mathrm{L}$ in each well) of a 96 well microtitre plate. The $1200 \mu \mathrm{L}$ solution was then placed back into the solution of their respective samples after each measurement. To measure a number of live bacteria in each treatment condition, bacteria solutions at the 0 -hr time point and 8-hr time point were used to spread onto tryptic soy agar plates. The agar plates were then incubated at $37^{\circ} \mathrm{C}$ for $12 \mathrm{hr}$. Numbers of the bacteria colonies from each plate were counted. 


\section{Results and Discussion}

\subsection{Deposition of silver nanoparticles onto HA by electrochemical reduction}

In the first electrochemical reaction stage, HA was crystallized onto a commercially pure titanium substrate using a current density of $12.5 \mathrm{~mA} / \mathrm{cm}^{2}$ at $\sim 95^{\circ} \mathrm{C}$ for 2 minutes, following the same procedure described in recent publications $[9,44]$. The electrochemical synthesis of HA under these conditions produces a uniform submicron thick layer of rod-shaped HA crystals. Previous studies have demonstrated that the longest crystal axis is associated with the crystallographic c-axis, and that there is some preferential orientation of the c-axis normal to the substrate $[45,46]$. The first electrochemical stage was kept constant in all experiments. In the second electrochemical reaction stage, the HA-coated titanium was transferred to a different electrolyte solution and used as the cathode for the electrochemical reduction of $\mathrm{Ag}^{+}$to $\mathrm{Ag}^{0}$.

In the second stage, the HA coated titanium was placed in a solution of 1.25 $\mathrm{mM} \mathrm{NaCl}$ while heating to $95^{\circ} \mathrm{C}$. When the desired temperature was obtained, $1.25 \mathrm{mM}$ of $\mathrm{AgNO}_{3}$ were added under vigorous stirring. Upon adding $\mathrm{AgNO}_{3}$, the precipitation of $\mathrm{AgCl}$ immediately occurred. The precipitation of $\mathrm{AgCl}$ was employed to keep the concentration of $\mathrm{Ag}^{+}$ions low and relatively constant. The solubility of $\mathrm{AgCl}$ in water at the reaction conditions results in a concentration of free $\mathrm{Ag}^{+}$ions of approximately $0.14 \mathrm{mM}$ [47]. After adding the $\mathrm{AgNO}_{3} 95^{\circ} \mathrm{C}$, a constant current density of of $12.8 \mathrm{~mA} / \mathrm{cm}^{2}$ (based on the surface area of the platinum anode) was applied for $90 \mathrm{~s}$ in order to electrochemically reduce $\mathrm{Ag}^{+}$ to $\mathrm{Ag}^{0}$ at the surface of the HA coated titanium cathode. Fig. 1a shows an SEM image of the Ag-HA coating formed under these conditions. The rod-shaped HA crystals are visible, having a morphology similar to that synthesized under similar conditions in previous studies [9,44]. Close inspection of the SEM image reveals that the HA crystals are covered by discrete nanoparticles less than $40 \mathrm{~nm}$ in diameter. It is assumed that the nanoparticles are metallic silver deposited onto the surface. Energy dispersive X-ray (EDX) analysis confirms the presence of silver, as seen in Table 1. All other elements detected in the EDX spectrum are associated with $\mathrm{HA}$ and the underlying titanium substrate.

Four samples synthesized under the same conditions as the sample shown in Fig. 1 were scraped off of the titanium substrate in order to obtain enough powder for XRD analysis of crystal structure. The XRD pattern from the collected powder is shown in Fig. 2. The pattern has a broad shoulder, indicating the presence of some amorphous material. The peaks in the XRD pattern were all matched to those of either metallic silver or HA powder according to the JCPDS standard 


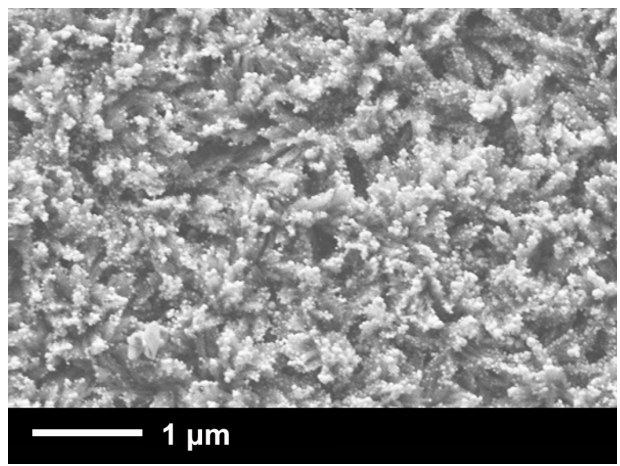

Figure 1: SEM image of a representative Ag-HA coating. Silver was electrochemically reduced using a constant current density of $12.8 \mathrm{~mA} / \mathrm{cm}^{2}$ applied for $90 \mathrm{~s}$.

\begin{tabular}{lll}
\hline Element & Wt\% & At\%] \\
\hline $\mathrm{O}$ & 27.7 & 53.5 \\
$\mathrm{P}$ & 4.4 & 4.4 \\
$\mathrm{Ca}$ & 6.3 & 4.8 \\
$\mathrm{Ag}$ & 7.4 & 2.1 \\
$\mathrm{Ti}$ & 54.3 & 35.1 \\
\hline
\end{tabular}

Table 1: Composition of Ag-HA coating as determined by energy dispersive X-ray spectroscopy on the sample shown in Figure 1.

patterns. The XRD pattern confirms the presence of metallic silver, and the ratio of peak height to width indicates that the crystal domain size is small. The Scherrer equation was used to estimate the size of silver crystals. The equation is written as:

$$
D=\frac{K \lambda}{\beta \cos (\theta)}
$$

where $\mathrm{D}$ is the mean size of the crystalline domain, $\mathrm{K}$ is the dimensionless shape factor, $\lambda$ is the $\mathrm{X}$-ray wavelength, $\beta$ is the line broadening at half the maximum intensity (FWHM), and $\theta$ is the Bragg angle. The calculated silver crystal size based on the (111) peak is $28 \mathrm{~nm}$. The crystal domain size is consistent with the size of the discrete spherical particles observed on the surface of HA crystals in SEM images of Ag-HA films.

Further confirmation of the presence of metallic silver particles was obtained using XPS of the Ag-HA coatings. The XPS spectrum is shown in Fig. 3. The peak positions were charge corrected relative to the $\mathrm{C} 1 \mathrm{~s}$ peak of adventitious carbon on the sample surface. The peaks located at $374.0 \mathrm{eV}$ and $368.0 \mathrm{eV}$ corre- 


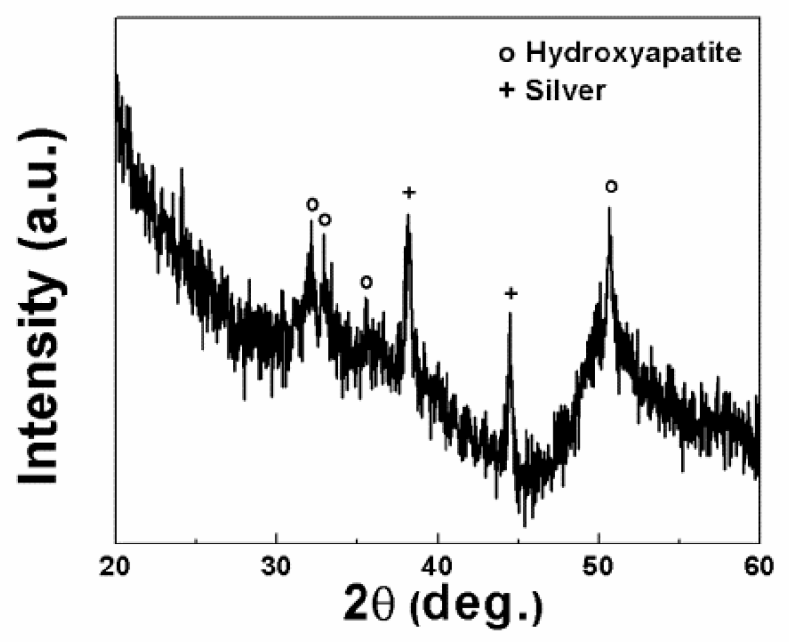

Figure 2: XRD pattern of Ag-HA coating obtained by applying a constant current density of 12.8 $\mathrm{mA} / \mathrm{cm}^{2}$ for $90 \mathrm{~s}$.

spond to $\mathrm{Ag} 3 \mathrm{~d} 3 / 2$ and $\mathrm{Ag} 3 \mathrm{~d} 5 / 2$, respectively. No other peaks were observed that could be attributed to other forms of silver. Since XPS is very sensitive to the elemental composition on the surface, the spectrum indicates that the nanoparticles observed on the HA coating are comprised of metallic silver.

It is believed that metallic silver is deposited on the surface due to the electrochemical reduction of $\mathrm{Ag}^{+}$through the cathodic reaction:

$$
\mathrm{Ag}^{+}+e^{-} \rightarrow \mathrm{Ag}(\mathrm{s})
$$

The reaction requires electrons to be transported from the cathode to silver cations adsorbed on the cathode surface. Since the cathode is almost completely covered by a layer of HA, the HA layer acts as a resistive barrier to electron transport. Cyclic voltammetry experiments on HA thin films have shown that HA becomes electrically conductive after applying a field strength of $15 \mathrm{kV} / \mathrm{cm}$ [48]. The HA layer on the cathode under these conditions is less than $1 \mu \mathrm{m}$ in thickness [9]. Therefore, a voltage drop across the HA film thickness of less than $1.5 \mathrm{~V}$ is sufficient to have significant electrical current through the HA coating. To maintain a constant current density of $12.8 \mathrm{~mA} / \mathrm{cm}^{2}$ under the conditions used for electrochemical reduction of silver, the required potential across the electrodes was over $20 \mathrm{~V}$ due to the relatively low ionic strength of the solution in equilibrium with 


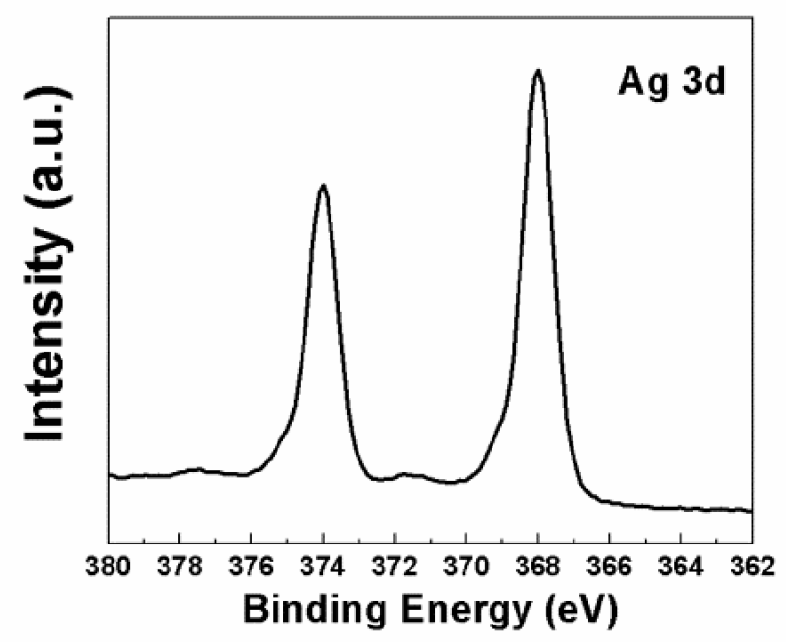

Figure 3: XPS spectrum of Ag-HA coating obtained by applying a constant current density of 12.8 $\mathrm{mA} / \mathrm{cm}^{2}$ for $90 \mathrm{~s}$.

precipitated $\mathrm{AgCl}$. The voltage drop across the $\mathrm{HA}$ layer is likely sufficient to allow electrical conduction through the coating. The presence of silver nanoparticles at the tips of rod shaped HA particles, as seen in Fig. 1a, is supporting evidence that the HA nanocrystals are electrically conductive during the synthesis so that $\mathrm{Ag}^{+}$is directly reduced on the surface.

The role of $\mathrm{NaCl}$ during synthesis is to lower and moderate the concentration of $\mathrm{Ag}^{+}$by precipitating solid $\mathrm{AgCl}$. To confirm this, two control experiments were carried out. In the first experiment, the same procedure used to produce the sample shown in Fig. 1a was followed except that $\mathrm{NaCl}$ was not added. In the second electrochemical reaction stage, the electrolyte solution consisted of 1.25 $\mathrm{mM}$ of $\mathrm{AgNO}_{3}$. An SEM image of silver nanoparticles deposited electrochemically from the $1.25 \mathrm{mM} \mathrm{AgNO}_{3}$ solution is shown in Fig. 4a. With the higher $\mathrm{Ag}^{+}$ concentration of $1.25 \mathrm{mM}$, the silver particles that are observed are much larger. Spheroidal silver particles are visible on the surface having diameters averaging approximately 75 to $100 \mathrm{~nm}$. In a second control experiment, the same procedure was used except that the $\mathrm{Ag}^{+}$concentration was reduced to $0.08 \mathrm{mM}$. To maintain similar ionic strength as that of the $1.25 \mathrm{mM} \mathrm{AgNO}_{3}$ solution, $1.25 \mathrm{mM} \mathrm{NaNO}_{3}$ was added to $0.08 \mathrm{mM} \mathrm{AgNO}_{3}$. An SEM image of the sample produced using 0.08 $\mathrm{mM} \mathrm{Ag}{ }^{+}$is shown in Fig. 4b. Using a lower $\mathrm{Ag}^{+}$concentration resulted in fine 
silver nanoparticles decorating the surface of the HA crystals. Close inspection of the SEM image shows that the silver nanoparticles are approximately $15-20 \mathrm{~nm}$ in average diameter. In a recent study, an electrochemical cathodic reaction was used to coprecipitate HA and Ag [49]. It was found that Ag nanoparticles could only be deposited by coordinating free $\mathrm{Ag}^{+}$ions with cysteine. Forming coordination complexes with $\mathrm{Ag}^{+}$has the effect of reducing the concentration of free silver cations available for electrochemical reduction. In the present study, precipitation of solid $\mathrm{AgCl}$ is a simple alternative that can be used to maintain low $\mathrm{Ag}^{+}$concentration. In principle, the electrolyte solution could be used repeatedly, as the silver ions consumed by electrochemical reduction can be replenished at the ion concentration in equilibrium with solid $\mathrm{AgCl}$. The control experiments indicate that low $\mathrm{Ag}^{+}$concentration is desirable for producing smaller nanoparticles.
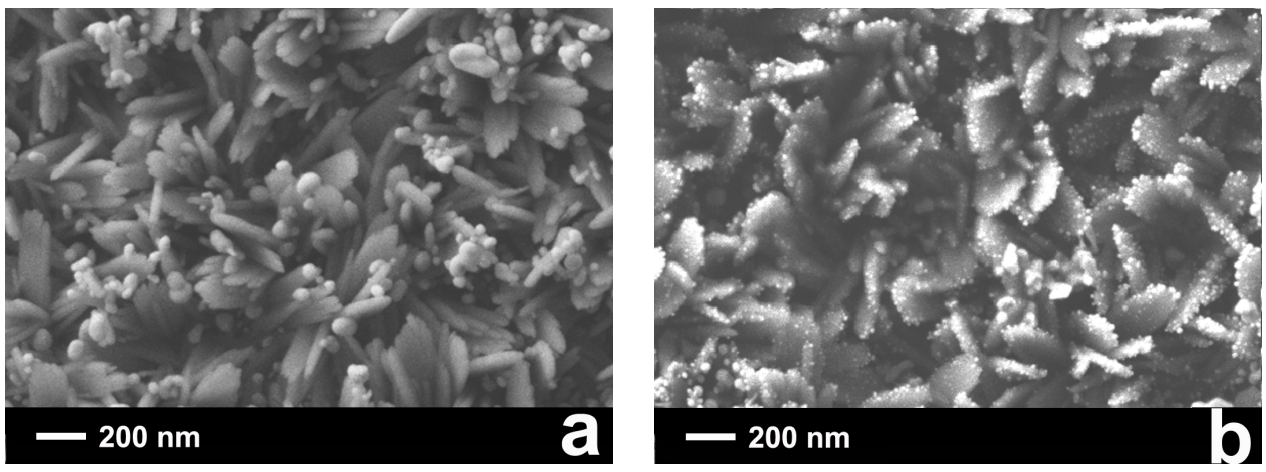

Figure 4: SEM images of Ag-HA coatings obtained by electrochemical reduction of $\mathrm{Ag}^{+}$in $90 \mathrm{~s}$ under a current denisty of $12.8 \mathrm{~mA} / \mathrm{cm}^{2}$ from a solution of (a) $1.25 \mathrm{mM} \mathrm{AgNO}_{3}$ and (b) $0.08 \mathrm{mM}$ $\mathrm{AgNO}_{3}+1.25 \mathrm{mM} \mathrm{NaNO}_{3}$

To examine the nanoparticle growth rate, the silver reduction reaction was carried at a fixed current density while varying the time that the current was applied. The applied current density was held constant at $12.8 \mathrm{~mA} / \mathrm{cm}^{2}$ using an electrolyte solution of $1.25 \mathrm{mM} \mathrm{AgNO}_{3}$ and $1.25 \mathrm{mM} \mathrm{NaCl}$. The reaction time was varied from $90 \mathrm{~s}$ to $300 \mathrm{~s}$, and the weight percentage of silver in the resulting samples was measured using EDX. Fig. 5a shows the silver weight percentage plotted versus time. If $\mathrm{Ag}^{+}$is available at the surface of the cathode, then the total mass of silver metal deposited on the surface is expected to be proportional to the total number of electrons transferred from the cathode. Under constant current density, the number of electrons transferred is related to the current density multiplied by the time that current is applied. In addition to electrons, the silver reduction reac- 
tion is also dependent on the availability of $\mathrm{Ag}^{+}$at the cathode surface. $\mathrm{As} \mathrm{Ag}^{+}$ ions at the cathode surface are consumed by the reduction reaction, the growth of silver nanoparticles requires the transport of $\mathrm{Ag}^{+}$to the cathode surface through diffusion and Coulombic attraction. If mass transfer of $\mathrm{Ag}^{+}$becomes limiting, then the silver metal deposition would slow down and would no longer be directly proportional to the quantity of electrons transferred. Instead, electrons would be consumed by the electrolysis of water, which is the primary competing Faradaic reaction. Over the time range investigated, the weight percent silver versus time is well represented by a linear fit, as seen in Fig. 5a. The results suggest that mass transfer of $\mathrm{Ag}^{+}$is not limiting the reaction in the time range investigated. As the reaction is carried out for longer time, the silver nanoparticles grow larger and more polydisperse. The SEM image in Fig. 5b shows the surface of the sample produced using the longest investigated time of $300 \mathrm{~s}$. The SEM image shows numerous polydisperse silver nanoparticles, with the largest near $200 \mathrm{~nm}$ in diameter.
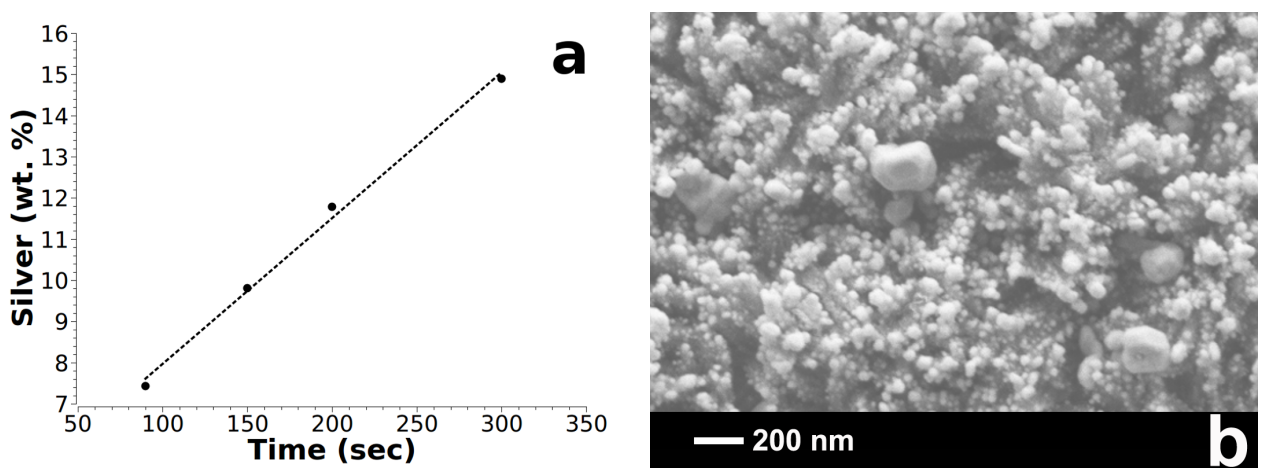

Figure 5: (a) Weight percent silver deposited versus time from $90 \mathrm{~s}$ to $300 \mathrm{~s}$. The dashed line is a linear fit of the data. (b) SEM image of the sample produced after $300 \mathrm{~s}$. Silver was electrochemically reduced using a constant current density of $12.8 \mathrm{~mA} / \mathrm{cm}^{2}$.

\subsection{Biomineralization from simulated body fluid}

Simulated body fluid (SBF) is a synthetic electrolyte solution that mimics the ionic strength, composition, and $\mathrm{pH}$ of human blood plasma [43]. When HA is submerged in SBF for extended time, additional calcium phosphate may be deposited from the SBF onto the HA surface. Calcium phosphate deposition from SBF offers an in vitro test of the activity of the HA surface for enhancing biomineralization. It is known that negative surface charge on HA promotes calcium 

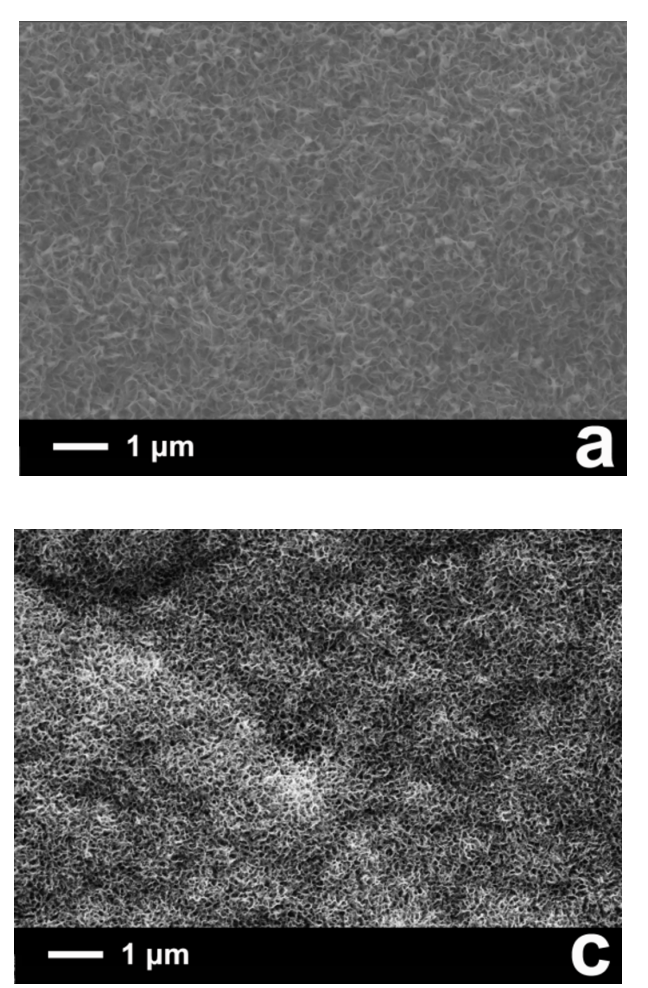

phosphate deposition, while positive surface charge retards calcium phosphate deposition [39]. Electrochemically synthesized HA thin films on titanium, similar to those in the present study, were recently shown to have strong negative surface charge as a result of quasi-permanent remnant electrical polarization acquired during synthesis [9]. To explore the in vitro activity of the Ag-HA thin films for promoting biomineralization, films were submerged in $1.5 \times \mathrm{SBF}$ at $37^{\circ} \mathrm{C}$ and $\mathrm{pH}=7.25$ for 24 hours. The solution used is called $1.5 \times \mathrm{SBF}$ to reflect that the ionic strength is $150 \%$ of that found in human blood plasma [43]. The higher ionic strength of the SBF increases the rate of calcium phosphate deposition, enabling shorter experimental times to observe deposition [39].
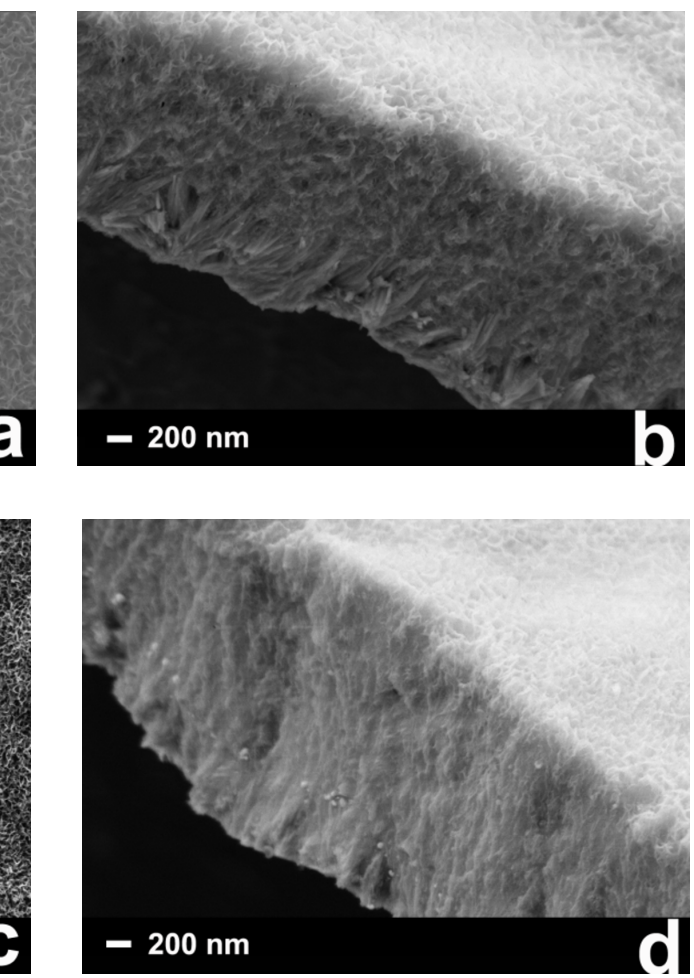

Figure 6: SEM images of HA and Ag-HA after exposure to $1.5 \times \mathrm{SBF}$ for $24 \mathrm{~h}$. (a) and (b) are top and side views of the HA coating, (c) and (d) are top and side views of Ag-HA coating.

In the SBF experiments, two types of samples were compared. The first sample was HA produced after the first stage without depositing Ag nanoparticles. The second sample was the Ag-HA sample in which Ag nanoparticles were deposited in a second stage of $12.8 \mathrm{~mA} / \mathrm{cm}^{2}$ current applied for $90 \mathrm{~s}$ using an elec- 
trolyte solution of $1.25 \mathrm{mM} \mathrm{AgNO}_{3}$ and $1.25 \mathrm{mM} \mathrm{NaCl}$ (the same conditions used for the sample shown in Fig. 1a). After 24 hours, a new porous calcium phosphate layer was deposited on both samples, as shown in Fig. 6. The top view images in Fig. 6a and Fig. 6b show a porous morphology consistent with calcium phosphate deposited from SBF onto HA under similar experimental conditions in previous studies [9, 39]. The surface morphology is similar for the HA and Ag-HA samples. The side view images shown in Fig. $6 \mathrm{~b}$ and Fig. 6d allow the thickness of the layer deposited from SBF to be estimated. For both the HA and Ag-HA samples, the layer deposited from SBF is approximately $1.2 \mu \mathrm{m}$ thick. In the side view images, the base of the coating is at the lower left, while the surface is at the upper right. Close examination of the SEM images shows the rod-shaped HA crystals synthesized electrochemically remain at the base of the coating. For the Ag-HA coating, Ag nanoparticles are visible in the side view image (Fig. 6d). The Ag nanoparticles appear as a line of bright dots in Fig. 6d located at a distance approximately $1 / 3$ of the total thickness from the base of the coating. The SBF experiments indicate that the electrochemical deposition of Ag has no measurable effect on the activity of the thin films in promoting in vitro biomineralization. The Ag nanoparticles appear to remain on the surface of the Ag-HA coating, where they can potentially provide long term antimicrobial activity.

\subsection{Antibacterial activity}

Antibacterial activity was measured by culturing E. coli in the presence of HA and Ag-HA coatings. The two types of coatings were prepared under the same experimental conditions to create the $\mathrm{HA}$ and $\mathrm{Ag}-\mathrm{HA}$ samples in the comparative SBF experiments described in the previous section, except the first stage HA deposition time was extended from $2 \mathrm{~min}$ to $5 \mathrm{~min}$, and the silver deposition time was extended to $6 \mathrm{~min}$. The longer silver deposition time was chosen based on preliminary experiments that showed higher silver loading was necessary to effectively kill E. coli. The Ag-HA samples made under these conditions had a silver content of approximately 6 atomic percent as measured by EDX. Each coating was applied to a flat plate of titanium having a total surface area of $1.56 \mathrm{~cm}^{2}$. Each coated titanium plate was submerged in $2 \mathrm{ml}$ of bacteria suspension, and bacteria growth was measured over time through light scattering at $490 \mathrm{~nm}$ from samples of the bacteria suspension. A total of $3 \mathrm{HA}$ coatings, $9 \mathrm{Ag}-\mathrm{HA}$ coatings, and 3 controls were compared. The control samples consisted of the bacteria suspension without a submerged titanium plate. Fig. 7 shows the results of bacteria growth over 8 hours, with light scattering at $490 \mathrm{~nm}$ reported in absorbance units. The control experiment shows the exponential increase in light scattering consis- 
tent with the uninhibited growth of bacteria. The light scattering is slightly lower in the presence of the HA coating, but within the range of error, indicating the HA coated titanium alone did not significantly affect bacteria growth. With the Ag-HA coating, there was significant variation in the results. In 6 out of 9 samples, bacteria growth was almost completely inhibited for 8 hours, as indicated by the low light scattering shown in Fig. 7 for the data labeled "Ag-HA". In the remaining $3 \mathrm{Ag}-\mathrm{HA}$ samples, no inhibition of bacteria was observed, When data from all 9 Ag-HA samples are included, as shown in Fig. 7 data labeled "Ag-HA (all samples)", the error bars are significantly greater, but still show statistically significant inhibition compared to the control and HA samples.

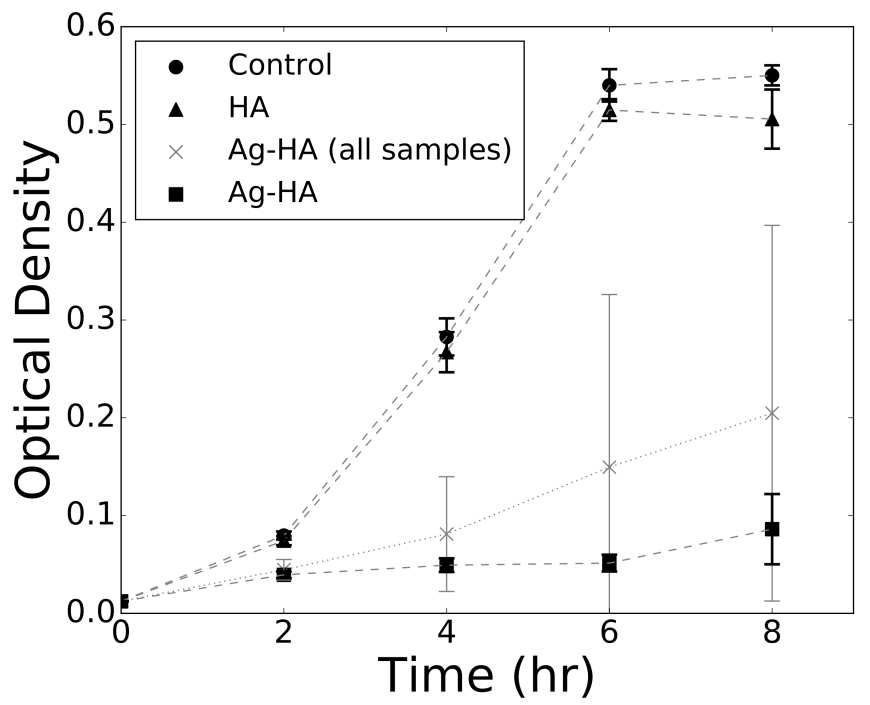

Figure 7: Growth of E. coli bacteria when exposed to HA and Ag-HA, as measured by light scattering. Data points indicate the mean value measured, and error bars indicate standard deviation.

To measure the number of live bacteria remaining, bacteria samples at the 0 $\mathrm{hr}$ and $8 \mathrm{hr}$ time points were spread onto agar plates and cultured at $37^{\circ} \mathrm{C}$. Fig. 8 shows the number of colony forming units counted after 12 hours on the agar plates. The $6 \mathrm{Ag}$-HA samples that were effective in inhibiting bacteria growth as measured by light scattering in Fig. 7 were also effective in killing nearly all bacteria, as indicated by the low number of colony forming units in Fig. 8. The HA coated titanium had no effect on the number of colony forming units as compared to the control. The Ag-HA samples that were most effective against E. coli killed nearly all of the bacteria very quickly after exposure. Bacteria may 
be killed upon direct contact with the silver nanoparticles, or through silver ions released in solution. One possible reason why a fraction of the Ag-HA samples were ineffective against the bacteria is the potential variability in bacteria contact with the surface. As the bacteria suspension was added to the well plate, some may bacteria sediment onto the surface, while others remain suspended or sediment in the well without contacting the silver surface. Another possibility is that the AgHA samples display variable silver ion release kinetics. Future work will analyze the concentration of silver ions released over time, as well cell culture directly on the Ag-HA surface in order to optimize silver loading for antibacterial activity and to investigate cytotoxicity.

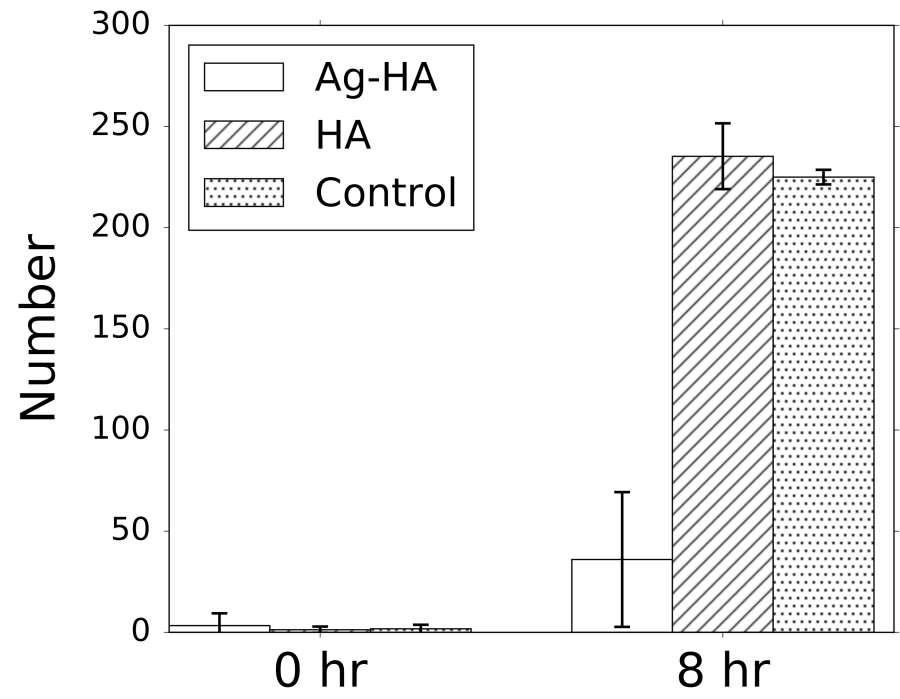

Figure 8: Number of E. coli colony forming units after $12 \mathrm{hr}$ growth onto agar plates at $37^{\circ} \mathrm{C}$ for bacteria exposed to $\mathrm{HA}$ and $\mathrm{Ag}$-HA samples for 0 and $8 \mathrm{hr}$ as compared to the control without a titanium plate. The height of the bars is the mean measured value and the error bars indicate standard deviation.

\section{Conclusions}

The two stage electrochemical method allows hydroxyapatite coatings to be prepared that are simultaneously bioactive and antimicrobial. Separating the HA film growth and Ag nanoparticle synthesis into different electrochemical stages allows the properties of both the HA coating and Ag nanoparticles to be easily 
controlled independently. Using low concentrations of $\mathrm{Ag}^{+}$in solution, metallic silver nanoparticles can be formed through electrochemical reduction on the HA coating surface. The silver loading on the surface is directly proportional to the time used for electrochemical reduction under constant current density. The technique therefore allows for low-cost and facile control of silver loading. The novel Ag-HA coating is shown to inhibit bacteria growth, suggesting that the coating may be used in biomedical implants to reduce the risk of infections following surgery. Further work is needed to optimize silver loading for antimicrobial activity, and to examine potential cytotoxicity. In addition, the results indicate that the nanoscale HA crystals are electrically conductive under moderate applied voltages, potentially allowing other electrochemical reactions to be carried out on the HA coating surface.

\section{Acknowledgments}

We acknowledge financial support from the University of Rochester, NSF (CMMI-0856128, IIP-1343083, CHE-1427882), and the DOE through the Laboratory for Laser Energetics (DE-FC03-92SF19460). We thank Christine Pratt for assistance with XRD measurement, and Dr. Takimoto of the University of Rochester Medical Center for supplying E. coli bacteria.

\section{References}

[1] S. V. Dorozhkin, Calcium orthophosphate deposits: Preparation, properties and biomedical applications, Materials Science \& Engineering C-Materials for Biological Applications 55 (2015) 272-326.

[2] R. Geesink, Hydroxyapatite-coated total hip prostheses: 2 year clinical and roentgenographic results of 100 cases, Clinical Orthopaedics and Related Research (261) (1990) 39-58.

[3] K. Soballe, E. Hansen, H. Brockstedtrasmussen, C. Bunger, Hydroxyapatite coating converts fibrous tissue to bone around loaded implants, Journal of Bone and Joint Surgery-British Volume 75 (2) (1993) 270-278.

[4] B. Sanden, C. Olerud, M. Petren-Mallmin, S. Larsson, Hydroxyapatite coating improves fixation of pedicle screws - a clinical study, Journal of Bone and Joint Surgery-British Volume 84B (3) (2002) 387-391. 
[5] K. Degroot, R. Geesink, C. Klein, P. Serekian, Plasma sprayed coatings of hydroxylapatite, Journal of Biomedical Materials Research 21 (12) (1987) 1375-1381.

[6] P. Li, K. deGroot, T. Kokubo, Bioactive (ca10)(po4)6(oh)2-tio2 composite coating prepared by sol-gel process, Journal of Sol-Gel Science and Technology 7 (1-2) (1996) 27-34.

[7] Y. Han, T. Fu, J. Lu, K. W. Xu, Characterization and stability of hydroxyapatite coatings prepared by an electrodeposition and alkaline-treatment process, Journal of Biomedical Materials Research 54 (1) (2001) 96-101.

[8] M. Shirkhanzadeh, Calcium-phosphate coatings prepared by electrocrystallization from aqueous-electrolytes, Journal of Materials Science-Materials in Medicine 6 (2) (1995) 90-93.

[9] C. Fu, K. Savino, P. Gabrys, A. Zeng, B. Guan, D. Olvera, C. Wang, B. Song, H. Awad, Y. Gao, M. Z. Yates, Hydroxyapatite thin films with giant electrical polarization, Chemistry of Materials 27 (4) (2015) 1164-1171.

[10] G.-J. A. ter Boo, D. W. Grijpma, T. E. Moriarty, R. G. Richards, D. Eglin, Antimicrobial delivery systems for local infection prophylaxis in orthopedicand trauma surgery, Biomaterials 52 (2015) 113-125.

[11] M. M. Tunney, G. Ramage, S. Patrick, J. R. Nixon, P. G. Murphy, S. P. Gorman, Antimicrobial susceptibility of bacteria isolated from orthopedic implants following revision hip surgery, Antimicrobial Agents and Chemotherapy 42 (11) (1998) 3002-3005.

[12] M. Kolar, K. Urbanek, T. Latal, Antibiotic selective pressure and development of bacterial resistance, International Journal of Antimicrobial Agents 17 (5) (2001) 357-363.

[13] L. G. Harris, R. G. Richards, Staphylococci and implant surfaces: a review, Injury-International Journal of the Care of the Injured 37 (2006) 3-14.

[14] D. Guin, S. V. Manorama, J. N. L. Latha, S. Singh, Photoreduction of silver on bare and colloidal tio2 nanoparticles/nanotubes: Synthesis, characterization, and tested for antibacterial outcome, Journal of Physical Chemistry C 111 (36) (2007) 13393-13397. 
[15] M. Lv, S. Su, Y. He, Q. Huang, W. Hu, D. Li, C. Fan, S.-T. Lee, Long-term antimicrobial effect of silicon nanowires decorated with silver nanoparticles, Advanced Materials 22 (48) (2010) 5463-5467.

[16] O. Choi, K. K. Deng, N.-J. Kim, L. Ross, R. Y. Surampalli, Z. Hu, The inhibitory effects of silver nanoparticles, silver ions, and silver chloride colloids on microbial growth, Water Research 42 (12) (2008) 3066-3074.

[17] R. Kumar, H. Munstedt, Silver ion release from antimicrobial polyamide/silver composites, Biomaterials 26 (14) (2005) 2081-2088.

[18] J. S. Kim, E. Kuk, K. N. Yu, J.-H. Kim, S. J. Park, H. J. Lee, S. H. Kim, Y. K. Park, Y. H. Park, C.-Y. Hwang, Y.-K. Kim, Y.-S. Lee, D. H. Jeong, M.-H. Cho, Antimicrobial effects of silver nanoparticles, NanomedicineNanotechnology Biology and Medicine 3 (1) (2007) 95-101.

[19] I. Sondi, B. Salopek-Sondi, Silver nanoparticles as antimicrobial agent: a case study on e-coli as a model for gram-negative bacteria, Journal of Colloid and Interface Science 275 (1) (2004) 177-182.

[20] L. Balogh, D. R. Swanson, D. A. Tomalia, G. L. Hagnauer, A. T. McManus, Dendrimer-silver complexes and nanocomposites as antimicrobial agents, Nano Letters 1 (1) (2001) 18-21.

[21] A. Melaiye, R. S. Simons, A. Milsted, F. Pingitore, C. Wesdemiotis, C. A. Tessier, W. J. Youngs, Formation of water-soluble pincer silver(i)-carbene complexes: A novel antimicrobial agent, Journal of Medicinal Chemistry 47 (4) (2004) 973-977.

[22] B. Le Ouay, F. Stellacci, Antibacterial activity of silver nanoparticles: A surface science insight, Nano Today 10 (3) (2015) 339-354.

[23] V. K. Sharma, R. A. Yngard, Y. Lin, Silver nanoparticles: Green synthesis and their antimicrobial activities, Advances in Colloid and Interface Science 145 (1-2) (2009) 83-96.

[24] A. R. Shahverdi, A. Fakhimi, H. R. Shahverdi, S. Minaian, Synthesis and effect of silver nanoparticles on the antibacterial activity of different antibiotics against staphylococcus aureus and escherichia coli, NanomedicineNanotechnology Biology and Medicine 3 (2) (2007) 168-171. 
[25] K. A. Bogle, S. D. Dhole, V. N. Bhoraskar, Silver nanoparticles: synthesis and size control by electron irradiation, Nanotechnology 17 (13) (2006) 3204-3208.

[26] H. Bar, D. K. Bhui, G. R. Sahoo, P. Sarkar, S. R. De, A. Misra, Green synthesis of silver nanoparticles using latex of jatropha curcas, Colloids and Surfaces A: Physicochemical and Engineering Aspects 339 (1-3) (2009) 134139.

[27] Z. T. Zhang, B. Zhao, L. M. Hu, Pvp protective mechanism of ultrafine silver powder synthesized by chemical reduction processes, Journal of Solid State Chemistry 121 (1) (1996) 105-110.

[28] K. S. Chou, C. Y. Ren, Synthesis of nanosized silver particles by chemical reduction method, Materials Chemistry and Physics 64 (3) (2000) 241-246.

[29] H. S. Wang, X. L. Qiao, J. G. Chen, S. Y. Ding, Preparation of silver nanoparticles by chemical reduction method, Colloids and Surfaces A: Physicochemical and Engineering Aspects 256 (2-3) (2005) 111-115.

[30] H. H. Nersisyan, J. H. Lee, H. T. Son, C. W. Won, D. Y. Maeng, A new and effective chemical reduction method for preparation of nanosized silver powder and colloid dispersion, Materials Research Bulletin 38 (6) (2003) 949-956.

[31] M. Epifani, C. Giannini, L. Tapfer, L. Vasanelli, Sol-gel synthesis and characterization of ag and au nanoparticles in sio2, tio2, and zro2 thin films, Journal of the American Ceramic Society 83 (10) (2000) 2385-2393.

[32] A. Taheri, M. Noroozifar, M. Khorasani-Motlagh, Investigation of a new electrochemical cyanide sensor based on ag nanoparticles embedded in a three-dimensional sol-gel, Journal of Electroanalytical Chemistry 628 (1-2) (2009) 48-54.

[33] M. A. Villegas, M. A. Garcia, S. E. Paje, J. Llopis, Parameters controlling silver nanoparticle growth in sol-gel silica coatings, Materials Research Bulletin 40 (7) (2005) 1210-1222.

[34] M. Roy, G. A. Fielding, H. Beyenal, A. Bandyopadhyay, S. Bose, Mechanical, in vitro antimicrobial, and biological properties of plasma-sprayed 
silver-doped hydroxyapatite coating, Acs Applied Materials \& Interfaces 4 (3) (2012) 1341-1349.

[35] W. Chen, Y. Liu, H. S. Courtney, M. Bettenga, C. M. Agrawal, J. D. Bumgardner, J. L. Ong, In vitro anti-bacterial and biological properties of magnetron co-sputtered silver-containing hydroxyapatite coating, Biomaterials 27 (32) (2006) 5512-5517.

[36] W. Chen, S. Oh, A. P. Ong, N. Oh, Y. Liu, H. S. Courtney, M. Appleford, J. L. Ong, Antibacterial and osteogenic properties hydroxyapatite coatings produced using of silver-containing a sol gel process, Journal of Biomedical Materials Research Part A 82A (4) (2007) 899-906.

[37] F. Bir, H. Khireddine, A. Touati, D. Sidane, S. Yala, H. Oudadesse, Electrochemical depositions of fluorohydroxyapatite doped by cu2+, zn2+, ag+ on stainless steel substrates, Applied Surface Science 258 (18) (2012) 70217030 .

[38] F. Pishbin, V. Mourino, J. B. Gilchrist, D. W. McComb, S. Kreppel, V. Salih, M. P. Ryan, A. R. Boccaccini, Single-step electrochemical deposition of antimicrobial orthopaedic coatings based on a bioactive glass/chitosan/nanosilver composite system, Acta Biomaterialia 9 (7) (2013) 7469-7479.

[39] K. Yamashita, N. Oikawa, T. Umegaki, Acceleration and deceleration of bone-like crystal growth on ceramic hydroxyapatite by electric poling, Chemistry of Materials 8 (12) (1996) 2697-2700.

[40] W. Wang, S. Itoh, Y. Tanaka, A. Nagai, K. Yamashita, Comparison of enhancement of bone ingrowth into hydroxyapatite ceramics with highly and poorly interconnected pores by electrical polarization, Acta Biomaterialia 5 (8) (2009) 3132-3140.

[41] S. Bodhak, S. Bose, A. Bandyopadhyay, Electrically polarized hap-coated ti: In vitro bone cell-material interactions, Acta Biomaterialia 6 (2) (2010) 641-651.

[42] P. N. Lim, L. Chang, E. S. Thian, Development of nanosized silversubstituted apatite for biomedical applications: A review, NanomedicineNanotechnology Biology and Medicine 11 (6) (2015) 1331-1344. 
[43] K. Hata, T. Kokubo, T. Nakamura, T. Yamamuro, Growth of a bonelike apatite layer on a substrate by a biomimetic process, Journal of the American Ceramic Society 78 (4) (1995) 1049-1053.

[44] C. Fu, B. Song, C. Wan, K. Savino, Y. Wang, X. Zhang, M. Z. Yates, Electrochemical growth of composite hydroxyapatite coatings for controlled release, Surface \& Coatings Technology 276 (2015) 618-625.

[45] X. Wei, C. Fu, K. Savino, M. Z. Yates, Carbonated hydroxyapatite coatings with aligned crystal domains, Crystal Growth \& Design 12 (7) (2012) 34743480 .

[46] X. Wei, C. Fu, K. Savino, M. Z. Yates, Fully dense yttrium-substituted hydroxyapatite coatings with aligned crystal domains, Crystal Growth \& Design 12 (1) (2012) 217-223.

[47] A. C. Melcher, The solubility of silver chloride, barium sulphate, and calcium sulphate at high temperatures., Journal of the American Chemical Society 32 (1910) 50-66.

[48] S. Hontsu, T. Matsumoto, J. Ishii, M. Nakamori, H. Tabata, T. Kawai, Electrical properties of hydroxyapatite thin films grown by pulsed laser deposition, Thin Solid Films 295 (1-2) (1997) 214-217.

[49] X. Lu, B. Zhang, Y. Wang, X. Zhou, J. Weng, S. Qu, B. Feng, F. Watari, Y. Ding, Y. Leng, Nano-ag-loaded hydroxyapatite coatings on titanium surfaces by electrochemical deposition, Journal of the Royal Society Interface 8 (57) (2011) 529-539. 